\title{
CONSEQUÊNCIAS PSICOLÓGICAS DA VIOLÊNCIA DOMÉSTICA SOFRIDA POR MULHERES: UMA REVISÃO BIBLIOGRÁFICA
}

\author{
Kelly Cristina Mancini de Lima ${ }^{1}$ \\ Mércia de Melo Rocha ${ }^{2}$ \\ Maria de Lourdes Gurian ${ }^{3}$ \\ Silvia Helena Modenesi Pucci ${ }^{4}$
}

RESUMO: Violência doméstica contra a mulher recebe esse nome porque ocorre nas dependências da residência, por ter ligação com familiares ou em uma relação íntima de afeto. As violências podem ir de lesões mais leves a transtornos psicológicos, entre outros. O objetivo deste estudo foi pesquisar e identificar a violência doméstica sofrida por mulheres; apontar os tipos de violência doméstica; identificar informações e dados de publicações a respeito das consequências psicológicas advindas da violência doméstica descritas na literatura. A metodologia consistiu em Revisão Bibliográfica entre os anos de 2010 a 2021 em bases de dados indexadas com periódicos e artigos científicos. Resultado: Identificou-se a relação dos tipos de violência doméstica e suas consequências psicológicas com foco no TEPT, ansiedade, depressão, vergonha, medo, culpa e outros não menos relevantes. Conclusão: Uma das possibilidades deste estudo foi identificar e propor novos dados para pesquisa quanto à violência doméstica e suas consequências psicológicas.

Palavras-chave: Violência doméstica. Consequências psicológicas. Mulheres.

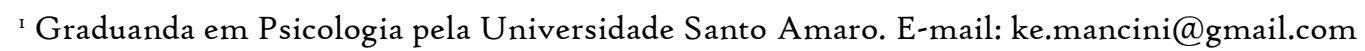

${ }^{2}$ Formação em Licenciatura em Estudos Sociais pela Faculdade de Filosofia, Ciências e Letras São Marcos. Habilitação em História e Geografia. Licenciatura em Pedagogia pela Universidade do Grande ABC. Habilitação em Supervisão Escolar e Habilitação em Administração Escolar. Atualmente Graduanda em Psicologia pela Universidade Santo Amaro.

3Professora graduada em Psicologia da UNISA e também colaboradora dos Centros de Estudos em Terapia Cognitivo Comportamental (CETCC), como orientadora e professora do curso de formação em Psicoterapia Cognitivo Comportamental. Tem experiência na área de Pesquisa em Psicologia, Supervisão Clínica com estágio em Psicologia Cognitivo Comportamental, Violência de Gênero, Violência Urbana, Educação e Políticas Públicas e Direitos Humanos. Especialista em Psicologia Cognitivo Comportamental pela Escola Paulista de Medicina e pela UNIFESP-EPM. Atuou como psicóloga no CRAVI - SJDC/SP como psicóloga, foi coordenadora do Centro de Referência e Apoio à Mulher Marcia Dangremon. http://lattes.cnpq.br/2186536627977218

4 Doutora em Psicologia da Saúde pela Universidade do Minho, UMINHO - Portugal (com revalidação pela Universidade de Campinas / UNICAMP, setor Medicina - Brasil). Pesquisadora Membro do Grupo de Estudos de Jovens Investigadores da Sociedade Portuguesa para o Estudo da Obesidade (SPEO). Pesquisadora Colaboradora no Grupo de Pesquisa da Universidade do Minho / Portugal: Processos Psicológicos Individuais e Familiares em Saúde e Doença. Mestre pelo Programa de Pós-Graduação em Psiquiatria e Psicologia Médica - UNIFESP. Especialista em PsicoOncologia pelo Hospital do Câncer/ SP, Especialista em Dependência Química (Universidade Federal de São Paulo/UNIFESP) e, Especialista em Promoção e Prevenção à Saúde em Álcool, Tabaco e Outras Drogas (UNIFESP). Coordenadora e Docente de Psicologia na Universidade Santo Amaro / UNISA - Brasil, em diversas disciplinas, bem como Supervisora hospitalar, Membro do NDE e atendimento junto alunos da Medicina - PAPU. Membro do Comitê de Ética e Orientadora de trabalhos científicos. Revisora de artigos Nacionais e Internacionais.

http://lattes.cnpq.br/o913875901013757 
ABSTRACT: Domestic violence against women is given this name because it occurs on the premises, because it is linked to family members or in an intimate relationship of affection. Violence can range from minor injuries to psychological disorders, among others. The aim of this study was to research and identify domestic violence suffered by women; point out the types of domestic violence; identify information and data from publications about the psychological consequences of domestic violence described in the literature. The methodology consisted of a Literature Review between the years 2010 to 202I in indexed databases with journals and scientific articles. Result: The relationship of the types of domestic violence and its psychological consequences was identified, with a focus on PTSD, anxiety, depression, shame, fear, guilt and others no less relevant. Conclusion: One of the possibilities of this study was to identify and propose new data for research on domestic violence and its psychological consequences.

Keywords: Domestic violence. Psychological consequences. Women.

\section{INTRODUÇÃO}

A desigualdade entre o homem e a mulher ocorre desde o século II a.C., tanto que na antiga Índia ocorreu a primeira ordem da sociedade com causa política e religiosa, a lei de Manu que dizia que a mulher jamais poderia se auto governar, mas sim depender de um homem, mesmo de parentes maritais (LAMBAZ, 2016).

Marinelli (2020) afirma que entre os séculos VIII a.C. e VI d.C., na civilização Grega o conhecimento e o trabalho eram negados às mulheres, cabia-lhes apenas o papel de casamento, reprodução de filhos e realização de tarefas domésticas. Enquanto em Roma, além dos papéis anteriores, a elas foi permitido a participação em banquetes, comparecer aos espetáculos e, raramente, participar de decisões políticas. Em concordância, Alves e Pitanguy (199I) pontuam que na Roma Antiga a posição social feminina era de inferioridade, tanto que o código legal legitimava a instituição jurídica do pater famílias, assim concedia ao homem total poder sobre a esposa, os filhos, os escravos e os servos.

$\mathrm{Na}$ sociedade feudal, século XI, um homem casado tinha a liberdade de apropriar-se dos bens de sua esposa, suas vestes, suas joias, roupas de cama, e ainda possuía o direito de espancá-la, isso se ela não realizasse os desejos de seu marido. $\mathrm{Na}$ maior parte das regiões, os homens podiam castigar suas esposas da forma que eles acreditavam ser ideal, com exceção de assassinato. $O$ espancamento, portanto, era uma realidade legalmente permitida, aprovada pelos costumes que autorizavam os maridos instituir a sua autoridade sobre a sua esposa (SANTOS, 2006). 
No século XVIII, evidencia-se a Revolução Francesa, período no qual as mulheres contestaram o autoritarismo e brigaram pela liberdade. Em razão da "Declaração dos Direitos do Homem”, Olympe de Gouges propôs em I791 a “Declaração dos direitos da mulher e da cidadã”, na qual defendia a liberdade da mulher e direitos iguais aos dos homens, como autonomia, propriedade, segurança e acima de tudo resistência à opressão. Todavia, Gouges foi guilhotinada em Paris no ano de 1793, tornando-se proibidas as organizações femininas (ASSMANN, 2007).

No final do século XVIII iniciou o período da Revolução Industrial, no qual as mulheres, assim como as crianças, tiveram que enfrentar o trabalho fabril, uma vez que os pagamentos dos trabalhadores, chefes de família, diminuíram e impossibilitaram o sustento familiar. Isso afetou drasticamente a vida das mulheres, visto que elas começaram a desempenhar dupla jornada de trabalho: em casa seguiram com os papéis de reprodução e atividades domésticas, e na fábrica realizando multitarefas. Dessa forma, recebiam salários menores aos dos homens, se remetendo a uma violenta exploração (BATISTA; BOTINNI, 2013).

Alves e Pitanguy (199I) discorrem que, até meados do século XIX, a mulher tinha a sua vida administrada de acordo com os interesses masculinos, com perfil de castidade e de resignação, cabendo-lhe obedecer às determinações do pai ou do marido. As mesmas autoras revelam que, no decorrer de várias décadas, as mulheres lutaram, brigaram, se manifestaram, fizeram reinvindicações por igualdade de direitos com relação ao gênero masculino. Com o movimento feminista conquistaram seu espaço na sociedade, obtendo o direito de votar, de ser votada e de trabalhar fora de casa.

Por fim, em um contexto mais atual, século XXI, Santos (2018) retrata o quanto a mulher é continuamente difamada e violada, reduzida à condição de "bem", "coisa", "objeto" de um homem. Sempre colocada em um lugar de inferioridade, de submissão, as campanhas publicitárias, cujo alvo é o homem, transmitem uma mensagem de que a mulher está ali para servir, ignorando todo o histórico de servidão e progresso na luta pelos direitos e igualdade, o que posteriormente foi chamado de Feminismo.

Garcia (2015) define feminismo como a obtenção de consciência da população feminina como humanidade geral, da opressão, do controle abusivo de que as 
mulheres foram e são instrumentos, objetos da sociedade masculina em diferentes períodos históricos, levando-as a procurar liberdade, independência do seu sexo e das modificações da população que fossem imprescindíveis para esta finalidade.

A partir das lutas, perdas e vitórias que constitui a História da Mulher, surge o feminismo, movimento vivo, sempre em recriação, que se une a outras organizações com o objetivo de confrontar os diferentes meios de discriminação (ALVES; PITANGUY, 1988).

Segundo Teles (2017), o feminismo é uma filosofia universal que acredita na existência da opressão (ideológica, cultural e política) direcionada às mulheres. Oferece um significado político, no sentido de fazer questionamentos sobre as relações de poder, de opressão, de exploração de pessoas ou grupos sobre os menos fortalecidos. Ainda propõe realizar transformações na sociedade, na economia e na política, inclusive por ter um caráter humanista à medida em que busca libertar as pessoas de ambos os sexos.

Paneghini (2018) retrata a existência de dois tipos de feministas: as liberais e as socialistas, enquanto as primeiras brigam por benefícios iguais dentro da sociedade capitalista, as segundas brigam ao lado das liberais pelas mesmas prerrogativas, mas visando construir uma sociedade sem classes e não oprimida ao lado da classe trabalhadora. A mesma autora indica que atualmente existe um bramido das mulheres repercutindo na sociedade, em virtude de ser um momento expressivo para o protagonismo feminino, o qual decorre em todas as circunstâncias da vida, principalmente nos locais da mídia, como novelas, redes sociais, entre outros.

Historicamente no Brasil, entre os anos de 1889 e 1930, a mulher operária trabalhava o dobro, e com salários mais baixos. Houve muitos movimentos nos quais as mesmas se destacavam, mas suas conquistas eram sempre em menor tamanho. Em 1906 foi realizado o primeiro Congresso Operário Brasileiro, no qual foi firmado a luta pela regulamentação do trabalho feminino (TELES, 2017).

Em junho de 1907, em São Paulo, aconteceram greves de tecelões, que em sua maioria eram mulheres, e a principal exigência era jornada de oito horas de trabalho. Durante esse período ocorreu o movimento pelo voto, que juntou uma parcela significativa de mulheres. Em 19ıo, a professora Deolinda Dalho fundou o Partido Feminino Republicano que defendia a liberação de cargos públicos a todos os 
brasileiros, sem distinção de gênero. Em 1917, aconteceu no Rio de Janeiro, promovida por Deolinda, uma passeata pelo direito ao voto feminino que se tornou uma realidade após a Revolução de 30 (TELES, 2017).

Em 1934, conforme Buonicore (2009), foi estabelecida a União Feminina, integrante da Aliança Nacional Libertadora (ANL), cujos membros apoiavam o socialismo, comunismo e anti-imperialismo. No ano seguinte o grupo foi cassado, a aliança foi esmagada e as principais líderes da União Feminina foram presas. Com o ocorrido, outras entidades femininas, assim como a Federação Brasileira pelo Progresso Feminino (FBPF), fundada em 1922 por Bertha Lutz, vivenciaram um golpe com a formação do Estado Novo em 1937.

Após o golpe de 1937, houve um retrocesso do movimento feminista, que se alonga até 1970 com o início de algumas manifestações, mesmo assim, durante este período as mulheres conseguiram atuar, como por exemplo no movimento contra a alta do custo de vida, realizado em 1950. Entre os acontecimentos que evidenciaram a entrada efetiva das mulheres, no âmbito público ressalta-se o Ano Internacional da Mulher, proclamado pela Organização das Nações Unidas (ONU) no ano de 1975 (OTTO, 2004).

Nos anos 8o, segundo Garcia (2015), o feminismo é centralizado no tema de diversidade no âmbito feminino, priorizando a multiplicidade de situações em que as mulheres se envolvem, o que interage com as variantes de gênero, etnia e preferência sexual. A autora afirma que, apesar de o feminismo tomar várias vertentes, a maior potência do movimento citado é de origem teórica de justiça efetiva e por ser uma teoria crítica afirmando que "o feminismo politiza tudo que toca".

Em agosto de 1985 foi criada a primeira Delegacia de Polícia de Defesa da Mulher (DDM) com apoio do Conselho Estadual da Condição Feminina e do governo do Estado de São Paulo. Pasinato e Santos (2008), referindo-se a primeira Delegacia da Mulher, afirmam que inicialmente atendeu a um número muito significativo de mulheres vítimas de violência, o que permite dizer que era um problema existente, grave e precisava ser visto por um serviço policial especializado. Como esta experiência foi um sucesso, novas delegacias da mulher foram criadas em São Paulo, e em outros estados, grupos feministas e de mulheres solicitaram que se criassem também unidades como parte integrante e principal de uma política pública 
específica para tratar da violência impetrada contra as mulheres.

Desse modo, segundo a pesquisa do Fórum Brasileiro de Segurança Pública, (FBSP) e o Datafolha (2016), todas as delegacias de polícia, especializadas e comuns, devem ser qualificadas para que possam atender as vítimas de estupro e declara que os direitos das mulheres e as questões de gênero devem ser tratados criteriosamente em todas as corporações policiais e em todas as instâncias de atendimento. De acordo com as mesmas fontes, é preciso condenar a violência contra as mulheres, porém ainda assim se faz necessário discutir nas instituições como extinguir a violência de gênero, para que as atitudes discriminatórias cessem de se reproduzir e as mulheres possam realmente ser ouvidas.

Pasinato e Santos (2008) ressaltam que as demandas feministas sofreram resistência governamental, como a seleção de policiais femininas para atuarem nas delegacias da mulher, assim os anos 90 foram marcados pelo desapontamento das feministas com as Delegacias da Mulher. Como não podiam ter acesso às políticas de segurança pública, passaram a focar a sua atenção para outras ações, como a criação de casas abrigo e serviços não criminais de atendimento a mulheres em situação de violência. As autoras afirmam que o modelo mais comum de Delegacia da Mulher é o que inclui serviços policiais, o qual oferece conselhos, faz mediação e investigação, além de atender os crimes de cunho sexual, ou não, efetuados por parceiros ou exparceiros das vítimas.

Paneghini (2018) discorre também que a mobilização feminina está inclusive nas ruas, em luta contra as atitudes que discriminam pessoas do sexo feminino. A autora traz como exemplo a Primavera das Mulheres, movimento de rua no Brasil, em 2015, com o objetivo de lutar contra a instrumentalização religiosa do Estado e as sugestões provenientes dos setores mais antidemocráticos e conservadoristas do Congresso, cuja meta era coibir o direito das mulheres de realizar o aborto nas situações em que já era permitido.

Conforme Saffioti (200I), em muitas sociedades os homens exercem o poder de determinar a conduta das mulheres e adolescentes, e são autorizados socialmente a castigar, punir o que consideram desvio, fazendo uso da violência. Segundo Krug et al. (2002), a violência pode ser definida ao utilizar força física contra si ou outra pessoa, com o risco de resultar em danos físicos, psicológicos ou até em óbito. 
Existem violência de gênero, violência contra mulheres, violência doméstica, violência intrafamiliar e diferenças entre elas. $O$ conceito de violência de gênero é o mais amplo devido ao fato de abranger vítimas como mulheres e adolescentes de ambos os sexos. A violência contra mulheres inclui vítimas somente do sexo feminino. Além disso, a autora relata que a violência praticada por mulheres é quase inexistente quando comparada a homens, mas muito relevante em relação a crianças e adolescentes e ocorre principalmente em casa, por isso a nomenclatura "violência doméstica" (SAFFIOTI, 200I).

Os homens acreditam ter o direito de exercer seu poder sobre as mulheres mesmo já separados, se elas forem independentes e pedirem a separação, esse fator ainda é mais forte. Associada a violência intrafamiliar, a autora afirma que tem sobreposição com a doméstica, por restringir-se a pessoas ligadas por parentesco consanguíneo ou por afinidade, o que agrava muito a situação do sujeito agredido, e ela exemplifica como é mais difícil psicologicamente ser violentada, por exemplo, por pai, avô, irmão do que por um estranho, visto que um familiar é sempre alguém em quem se confia e de quem se espera proteção (SAFFIOTI, 200I).

Schraiber et al. (2005) afirmam que as mulheres podem estar envolvidas no contexto de violência doméstica tanto como agredidas, quanto agressoras, e não poucas vezes são nas duas formas, pois sofrem violência impostas pelo companheiro e ainda batem nos filhos.

Por sua vez, Pereira et al. (2021) afirmam que violência doméstica é compreendida como uma questão globalmente interligada à uma problemática que acomete a mulher no setor da saúde pública que indefere de seu poder aquisitivo, âmbito cultural, profissional ou religioso.

Segundo a Organização Pan-Americana da Saúde (OPAS, 2018), a violência física ou sexual realizada pelo próprio companheiro atinge $60 \%$ da população feminina em alguns países das Américas. De acordo com o estudo, o índice mais alto da região pertence à Bolívia, a qual atinge $58,5 \%$ do público feminino, em seguida o Equador apresentando 40,4\%, e logo após os Estados Unidos com 37,7\%. O estudo ainda aponta que, no Estado Brasileiro, aproximadamente $17 \%$ das mulheres de is a 49 anos sofrerão deste ato abusivo em algum instante das suas vidas. 
Schraiber et al. (2005) definem violência como atos dirigidos contra a mulher que podem ser agressões físicas, ameaças, destratos psicológicos, abusos e ainda assédios sexuais. Exemplifica como falas rudes, humilhações, tapas, beliscões ou empurrões que podem chegar a socos, à quebra de braço, perna, nariz, queimaduras, tiros, uso de arma branca, ameaças diversas, sexo forçado por medo ou por coerção física, espancamentos, dentre tantas outras formas.

Conforme Moura et al. (2009), historicamente qualquer tipo de violência contra a mulher tem sido aceita, suavizada e naturalizada no dia a dia das interações em diversas sociedades. Os autores constatam que, no Brasil, apenas ao final do século $\mathrm{XX}$, essas violências passaram finalmente a ser vistas politicamente como violação aos direitos humanos. Os autores ainda afirmam que os parceiros íntimos são os que provocam violências mais severas às mulheres e as atinge de $15 \%$ a $25 \% \mathrm{em}$ local doméstico.

Em conformidade, Blay (2003) explica que mesmo entre países civilizados, independente de seus regimes políticos e econômicos, existem quadros de violência contra mulheres de todas as idades: assassinatos, agressões e estupros, variando na intensidade com a qual a agressão ocorre.

Por sua vez, Schraiber et al. (2005) trazem que, embora viver a violência de forma grave ou repetidas vezes para as mulheres seja algo muito frequente, nem sempre elas percebem isso como violência. Acreditam ser as responsáveis por terem provocado as agressões, as humilhações ou mesmo os abusos ocorridos, em razão de seu próprio comportamento inadequado ou o de todas as mulheres, devido ser parte da sua "essência natural" apresentarem atitudes "provocadoras".

Ainda de acordo com os autores, muitas mulheres pensam que a violência é apenas aquela provocada por estranhos, que ocorre fora de casa, sendo somente agressões físicas e/ou sexuais. Pelo fato dessas mulheres terem essa visão deturpada de violência, os mesmos autores falam que esse fator gera dificuldade para que elas percebam que a situação doméstica, dentre ofensas verbais ou formas físicas isoladas menos graves são meios de violências. Ressaltam que em termos de valor ético e de direitos humanos, qualquer situação de violência é grave.

No ano de 2006, criou-se a Lei n. II.340 que previne e coíbe a violência doméstica e familiar sofrida por mulheres brasileiras. Nas definições de violência 
discorridas nessa lei estão inclusas violência sexual, psicológica, patrimonial, física e moral (BRASIL, 2006).

Em relação a violência sexual, segundo a publicação do Instituto de Pesquisa Econômica Aplicada (IPEA, 2014), no que se refere a violência sexual, a maioria das pessoas responsabilizam as mulheres por usarem roupas provocantes, e também por não terem comportamentos adequados ao que geralmente se "espera de uma mulher decente", como "ser uma respeitável mãe de família". Portanto, no quesito direito das mulheres sobre seus corpos, o IPEA (2014) afirma que ainda é uma luta a ser vencida.

De acordo com o Fórum Brasileiro de Segurança Pública (FBSP) e o Datafolha (2016), em uma pesquisa realizada (30\%) entre homens e mulheres igualmente concordam que a forma como as mulheres se vestem propicia a agressão sexual, ou seja, optar por determinadas peças de roupas as fazem culpadas por serem agredidas.

Quanto a violência psicológica, recentemente no dia 28 de julho de 2021 foi sancionada no Brasil a Lei n. I4.188 que:

Define o programa de cooperação Sinal Vermelho contra a Violência Doméstica como uma das medidas de enfrentamento da violência doméstica e familiar contra a mulher previstas na Lei $\mathrm{n}^{\mathrm{O}}$ II.340, de 7 de agosto de 2006 (Lei Maria da Penha), e no Decreto-Lei no 2.848 , de 7 de dezembro de 1940 (Código Penal), em todo o território nacional; e altera o Decreto-Lei no 2.848, de 7 de dezembro de 1940 (Código Penal), para modificar a modalidade da pena da lesão corporal simples cometida contra a mulher por razões da condição do sexo feminino e para criar o tipo penal de violência psicológica contra a mulher (BRASIL, 202I).

Sendo assim, essa Lei respalda de forma técnica e jurídica os casos nos quais muitas mulheres declaram que nunca foram fisicamente agredidas por seus companheiros, e a partir de agora será possível caminhar para enfrentar melhor a violência doméstica cometida contra as mulheres no Brasil (AGÊNCIA PATRÍCIA GALVÃO, 2021).

De acordo com Fernandes, Ávila e Cunha (2021), mesmo a Lei Maria da Penha contemplando a violência psicológica no art. $7^{\mathfrak{o}}$, inc. II, somente com a Lei $\mathrm{n}$. I4.I88/202I passou a ter um tipo penal correspondente. Apenas constava essa forma de violência, definida como uma "violação dos direitos humanos" no art. 6o e, ao mesmo tempo, a conduta correspondente não configura necessariamente um ilícito 
penal e muitas condutas consistentes em violência psicológica, como manipulação, humilhação, ridicularização, rebaixamento, vigilância, isolamento - não configuravam, na imensa maioria dos casos, infração penal. Apesar de serem ilícitos civis, não configuravam crime. As vítimas iam registrar boletins de ocorrência por violência psicológica e descobriam que tais ações não eram infração penal e nem contravenção. $O$ fato de não ter nem tipificação tornava muito complicado deferir medidas protetivas de urgência. Com a inserção do art. I47-B no Código Penal, esse hiato é preenchido e passa a ser crime praticar violência psicológica contra a mulher. Tutela-se, no "novel" crime, o direito fundamental "a uma vida livre de violência, tanto na esfera pública como na esfera privada" (Convenção de Belém do Pará, Decreto n. $1.973 / 1996$, art. $3^{\circ}$ ), principalmente a liberdade da mulher que sofreu a afronta ao direito de viver sem medo, traumas ou vulnerabilidades emocionais determinados ardilosamente por terceiro.

A Lei n. II.340, mais conhecida como a Lei Maria da Penha, criou mecanismos para controlar a violência doméstica e familiar contra as mulheres, e para isso faz uso da definição de violência da Convenção de Belém do Pará (que enxerga a violência contra a mulher como qualquer ato ou atuação baseado no gênero, que provoque morte, destruição ou tormento físico, sexual ou psicológico à mulher, no campo público e privado). Isso retratou um marco para o progresso das políticas relativas aos direitos humanos, sexuais e reprodutivos das mulheres, estimando-se a concepção de gênero para compreendê-la. A Lei em questão prevê ainda medidas integradas de prevenção à violência contra a mulher, dispõe sobre a assistência e o atendimento policial dirigido ao público feminino que sofreu violência no âmbito doméstico, familiar ou de afeto, cria medidas protetivas de urgência e Juizados de Violência, confirmando o direito à assistência judiciária e equipe multidisciplinar de apoio aos juizados e às mulheres (PRATES, 2013).

A respeito da violêcia patrimonial, segundo Pereira et al. (2013, p.04), presume-se a possibilidade de muitas mulheres não terem conhecimento que a "retenção, subtração, destruição parcial ou total de seus objetos pessoais" possam ser julgadas como um crime já descrito na lei Maria da Penha, não o identificam como tal e não denunciam essa forma de agressão. Diante disso, a violência patrimonial dificilmente se mostra isolada das demais, portanto, durante as discussões o agressor 
utiliza-se do método de abstrair as posses da vítima para que a mesma se silencie e permaneça na situação de agressão.

De acordo com Souza et al. (202I), a violência moral, presente na lei Maria da Penha supracitada, consiste em qualquer ato que contenha injúria, difamação ou calúnia. $\mathrm{O}$ ato de xingar, vazar fotos ou vídeos íntimos da vítima com o intuito de difamar, fazer com que ela se sinta injuriada também é configurado violência moral.

$\mathrm{Na}$ sequência serão abordados os fatores de risco da violência, diante dos quais Hayeck (2009) declara que a agressão não deva ser tratada como única e singular, e sim como um fato inserido no dia a dia da sociedade que se manifesta de várias formas e contêm-se múltiplas causas. Desta forma, a autora destaca algumas razões de a violência ocorrer, como o mau desempenho da justiça, a impunidade, a crise no sistema da educação e da saúde, a corrupção, a influência dos meios midiáticos, a ineficiência de políticas públicas como uma forma de intervir e prevenir a violência, entre outros.

\section{FATORES DE RISCO DA VIOLÊNCIA CONTRA A MULHER}

Conforme a autora acima mencionada, não se deve trivializar a violência antes de estudá-la e averiguá-la e afirma também que se deve questionar como a violência inseriu-se no cotidiano, como o Estado tem dado importância a este tema, que é necessário tratar as causas dessa práxis.

Schraiber et al. (2005) definem direitos humanos como próprios de todas as pessoas, sem distinção de nacionalidade, gênero e raça e explanam violência como transgressão ética nas relações interpessoais dos direitos humanos. Assim sendo, o Estado deveria garantir às mulheres o direito a não violência à sua vida, à igualdade política e ao poder de se reproduzir. O fato de o Estado não ter o poder de interferir no lar e na família permitiu que a violência doméstica cotidiana contra mulheres e crianças se tornasse invisível dentro desse espaço. Deveria ser um ambiente de paz, mas muitas vezes é de tensão. Segundo os autores, esses conflitos são de ordens variadas, como desemprego, maior ascensão feminina, entre outros.

Zaleski et al. (2010) afirmam que a violência pode ocorrer também devido ao consumo de álcool e apontam em suas pesquisas, com um público geral, que uma enorme quantidade de pessoas está sob efeito provocado pelo uso de álcool no 
momento no qual a violência acontece. Ainda de acordo com os autores, pessoas que consomem bebidas alcoólicas de maneira excessiva, consumidores sem nenhum controle e aqueles com outras dificuldades concernentes ao álcool, têm maiores chances de se ligarem a relacionamentos violentos do que os que se privam ou bebem de forma moderada.

Em concordância com os autores acima, pode-se destacar a cartilha preparada pela Secretaria Nacional de Políticas para as Mulheres (SNPM, 2020). De acordo com o documento (p.I4), existem algumas situações que favorecem a possibilidade de a mulher entrar em uma situação de risco de violência, são eles:

\begin{abstract}
Isolamento social; ausência de rede de serviços de saúde e proteção social bem estruturada e integrada; pouca consciência de direitos; histórico de violência familiar; transtornos mentais; uso abusivo de bebidas e drogas; dependência afetiva e econômica; presença de padrões de comportamento muito rígidos; exclusão do mercado de trabalho; deficiências; vulnerabilidades relacionadas a faixas etárias, raça/etnia e escolaridade.
\end{abstract}

O Anuário Brasileiro de Segurança Pública descreve que, no ano de 2020, período que abrange a pandemia de COVID-ı, foram realizadas no Brasil um mínimo de 694.13ı ligações à Polícia Militar referentes à violência doméstica, ou seja, para cada minuto houve I,3 chamadas de vítimas ou de outras pessoas solicitando apoio para ocorrências desse tipo de violência (BUENO; BOHNENBERGER; SOBRAL, 202I).

Para erradicar essa violência é preciso nomeá-la como tal e certamente será uma mudança cultural, resultado da luta de muitas mulheres e de alguns homens para que haja igualdade dos direitos entre os sexos e para que se possa ganhar uma ética de relações interpessoais que ofereça as mulheres mais dignidade (SCHRAIBER et al., 2005).

Por sua vez, o Conselho Federal de Psicologia (CFP, 2016) proferiu uma nota de suporte direcionado ao profissional dessa área, no que tange a ocorrência de violência contra mulheres, casos em que se deve quebrar o sigilo profissional e denunciar aos órgãos responsáveis. O conselho renova seu compromisso de construir uma sociedade com mais equidade e menos violência para a população feminina, começando pela notificação de todos os acontecimentos violentos contra a mulher atendida pelos profissionais da saúde, seja em casos nos quais a vida dela esteja em risco, ou a de seus terceiros. 


\section{CONSEQUÊNCIAS E TRAUMAS DA VIOLÊNCIA CONTRA MULHERES}

Pereira et al. (2021) consideram violência doméstica um problema de saúde mundial que tem como caraterística qualquer conduta dentro de um relacionamento estreito que possa causar prejuízos físicos, psicológicos ou sexuais e grandes efeitos na saúde mental das vítimas como "trauma interpessoal, e os sintomas de transtorno de estresse pós-traumático". O autor acresce sintomas “comórbidos, como depressão, ansiedade, suicídio, abuso de substâncias e distúrbios do sono" são os danos psicológicos mais mencionados por vítimas dessa violência.

Slegh (2006) relata que as mulheres vítimas de violência doméstica para muitos aparentam ser loucas, no entanto, elas passaram por tamanho sofrimento que as afetaram a ponto de virem suas vidas modificadas e muitas vezes destruídas. A mesma autora afirma que é preciso considerar os aspectos sociais, econômicos, culturais e políticos, mas que o sofrimento pessoal dessas mulheres após passarem por tais brutalidades fosse priorizado. Além disso, a autora coloca que as consequências da violência contra a mulher atingem também a sua família e a sua comunidade.

Em concordância com a autora acima, Pitta e Oliveira (2012) afirmam que a violência doméstica, além de ser prejudicial para a mulher que a sofre no âmbito psicofísico, atinge igualmente a família devido à situação doentia e desarmônica que ela provoca. Os autores ainda afirmam que muitas vezes a violência psicológica sofrida por mulheres é silenciosa, podendo ser inaudível aos familiares, parentes e conhecidos mais próximos da mulher que a sofre.

É possível afirmar que Pitta e Oliveira (2012) concordam mais uma vez com Slegh (2006) em relação as mulheres que sofrem violência doméstica, e estas, além de terem suas vidas transformadas, suas famílias e comunidade também as tem. Essa concordância se dá quando Slegh (2006) afirma que a mulher vítima de violência se vê afetada nos vários papéis que vivencia: mãe, esposa, mantenedora, entre outros. Os autores incluem também as crianças que fazem parte desse contexto e são afetadas de forma mental ao se tornarem vítimas ou perpetuadoras dessa violência na sua vida adulta. Por sua vez, Pitta e Oliveira (2012) pontuam que a mulher agredida sofre trauma transgeracional, ou seja, um impacto transferido a novas gerações. 
Crepschi (2005) constata que a mulher vítima de violência sexual tem medo durante um tempo e depois diminui a intensidade, possibilitando assim inclusão ao dia a dia. O caráter de culpa se faz presente, segundo a autora, quando a mulher crê que seria capaz de impedir o acontecimento agressivo, procurando justificativa para o fato, quando na verdade não há. A autora pontua que a raiva aparece depois da violência sofrida, manifestando a procura por vingança em razão do ocorrido, portanto, a conduta de vitimização pode acontecer abrangendo a raiva.

No âmbito da saúde, a OPAS (2018) afirma que a violência contra a população feminina tem sequelas que implicam feminicídio, autocídio, lesões, doenças como Vírus da Imunodeficiência Humana (HIV), infecções transmitidas pelo sexo, gravidez indesejada, transtornos mentais, entre outros.

Dessa forma, o Conselho Nacional de Justiça (CNJ) divulgou que mais de um milhão de processos de violência doméstica contra a mulher tramitaram na justiça brasileira no ano de 2016. Além disso, a cada cem mulheres existe um processo que trata desse tipo de violência, dentre esses, 13,5 mil correspondem a casos chamados de feminicídios (BANDEIRA, 2017).

\section{FEMINICÍDIO}

Em março de 2015 foi sancionada a lei do Feminicídio (Lei n. 13.104/2015) qualificada como crime hediondo (Lei n. 8.072/1990) e torna-se mais grave ao ocorrer em momentos de fragilidade, como quando a mulher está em gestação, ou por ela ser menor de idade, ou na presença dos filhos, entre outros (BRASIL, 2015).

Waiselfisz (2015) considera que a lei compreende a existência de feminicídio quando a agressão abrange violência doméstica e familiar, ou quando enfatiza-se descaso, intolerância à natureza feminina, qualificando crime devido ao simples fato de a vítima ser do sexo feminino. Sendo assim, o autor conclui que as agressões são feitas contra uma mulher de forma intencional, causando danos e prejuízos à sua saúde, podendo levar a sua morte.

Segundo IPEA (2021), em 2019 ocorreu no Brasil 3.737 homicídios de mulheres, um número menor ao ser comparado ao ano de 2018 que obteve 4.519 assassinatos do mesmo sexo, apontando uma redução de 17,3\% aproximadamente. Essa quantidade de mortes do público feminino em 2019 equivale a 3,5 vítimas para cada roo mil mulheres 
residentes no Brasil, a qual evidencia uma diminuição de $17,9 \%$ em comparação a 2018, quando teve o registro de 4,3 vítimas para cada roo mil habitantes do sexo feminino.

Ainda de acordo com o IPEA (202I), ao estudar a diferença nas taxas de assassinatos do público feminino no Brasil, no período de 2009 a 2019, observou-se que, apesar de ter ocorrido uma diminuição de $18,4 \%$, no entanto, houve um aumento de homicídios em I4 dos 27 estados do país, os quais destacam-se Acre, Rio Grande do Norte, Ceará e Amazonas.

\section{METODOLOGIA}

A pesquisa se deu através de uma revisão bibliográfica, que na visão da autora Tozoni-Reis (2009), busca entender profundamente o tema que se estuda através de leituras de produções literárias que abordem o mesmo tema ou similares.

O objetivo foi trazer à pesquisa sistematizações para refletir a respeito dessa temática, portanto, constituiu-se particularmente por periódicos e artigos científicos que abordaram o tema escolhido, disponíveis em endereços eletrônicos como:

Biblioteca Virtual em Saúde (BVS), Literatura Latino Americana e do Caribe em Ciências da Saúde (LILACS), Coordenação de Aperfeiçoamento de Pessoal de Nível Superior (CAPES), Brazilian Journal of Health Review (BJHR) e Scientific Electronic Library Online (SCIELO).

Foram utilizados materiais publicados através do cruzamento das palavraschaves: "consequências psicológicas e violência doméstica". Dentre os artigos científicos encontrados, foram selecionados os que estavam disponíveis em português, entre os anos de 2010 a 202I, e os que contemplavam o objetivo geral da presente pesquisa.

Foram excluídos artigos anteriores ao intervalo de tempo estabelecido, aqueles que abordavam a temática em outros idiomas, os que fugiam completamente ao tema proposto e os que traziam abordagens similares, mas com outros enfoques.

\section{RESULTADO}

Após submeter os artigos encontrados aos critérios de inclusão e exclusão, selecionaram-se cinco para contribuir com o presente estudo. 
Quadro I - Caracterização dos artigos selecionados a respeito das consequências psicológicas

\begin{tabular}{|c|c|c|c|}
\hline AUTORES & OBJETIVO & MÉTODO/AMOSTRA & RESULTADO \\
\hline $\begin{array}{l}\text { RODRIGUES, } \\
\text { R. F. (2010) }\end{array}$ & $\begin{array}{l}\text { Compreender o processo } \\
\text { de construção da } \\
\text { resiliência em mulheres } \\
\text { que vivenciaram a } \\
\text { violência sexual. }\end{array}$ & $\begin{array}{l}\text { Pesquisa qualitativa do tipo } \\
\text { exploratório / Mulheres acima de } \\
\text { I9 anos de idade em situação de } \\
\text { violência sexual e que foram } \\
\text { atendidas no IMMFM/SMS/RJ } \\
\text { entre jan. de } 2007 \text { e dez. de } 2008 \text {. }\end{array}$ & $\begin{array}{lr}\text { Sentimentos de } & \text { medo, } \\
\text { tristeza, raiva, culpa, perda; } & \text { vergonha, } \\
\text { ansiedade, } & \text { social, } \\
\text { isolamento } & \text { baixa } \\
\text { desconfiança, } & \text { autoestima, desmotivação e } \\
\text { desvalorização. }\end{array}$ \\
\hline $\begin{array}{l}\text { SOUZA, F. B. } \\
\text { C. de et al. (2012) }\end{array}$ & $\begin{array}{l}\text { Verificar } r \\
\text { psicológicos de mulheres } \\
\text { que sofrem violência } \\
\text { sexual. }\end{array}$ & $\begin{array}{l}\text { Estudo de revisão/Mulheres } \\
\text { sexualmente violentadas. }\end{array}$ & $\begin{array}{l}\text { Transtorno de Estresse Pós- } \\
\text { Traumático-TEPT, } \\
\text { depressão, ansiedade, } \\
\text { transtornos alimentares, } \\
\text { distúrbios sexuais e } \\
\text { distúrbios do humor. }\end{array}$ \\
\hline $\begin{array}{l}\text { SOARES, M. C. } \\
\text { da S. et al. (2014) }\end{array}$ & $\begin{array}{l}\text { Identificar sentimentos } \\
\text { de mulheres vítimas de } \\
\text { violência doméstica. }\end{array}$ & $\begin{array}{l}\text { Pesquisa exploratória, descritiva, } \\
\text { de abordagem qualitativa } \\
\text { Mulheres entre } 20 \text { e } 68 \text { anos, com } \\
\text { baixa escolaridade, convivendo em } \\
\text { união estável, com o número de } \\
\text { filhos entre um a treze filhos, } \\
\text { sendo o tempo de convívio } \\
\text { violento variante entre três e vinte } \\
\text { e cinco anos. }\end{array}$ & $\begin{array}{l}\text { Medo, angústia, a culpa e as } \\
\text { preocupações em relação ao } \\
\text { futuro, baixa autoestima, a } \\
\text { desvalorização de si mesma. }\end{array}$ \\
\hline $\begin{array}{l}\text { OLIVEIRA, L. } \\
\text { N. et al. (2017) }\end{array}$ & 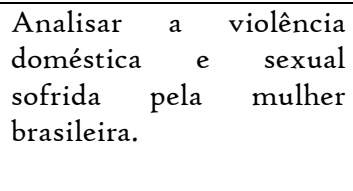 & $\begin{array}{l}\text { Revisão integrativa da literatura/ } \\
\text { Mulher brasileira que sofreu } \\
\text { violência doméstica e sexual ( } 2007 \\
\text { à 20II). }\end{array}$ & $\begin{array}{l}\text { Medo, ansiedade, vergonha, } \\
\text { isolamento social, insônia, } \\
\text { sentimento de inferioridade } \\
\text { e culpa, depressão, aborto } \\
\text { espontâneo. }\end{array}$ \\
\hline $\begin{array}{l}\text { PEREIRA, J. C. } \\
(202 \mathrm{I})\end{array}$ & $\begin{array}{l}\text { Apresentar o contexto } \\
\text { histórico da violência } \\
\text { contra as mulheres e suas } \\
\text { consequências } \\
\text { os'icológicas. }\end{array}$ & $\begin{array}{l}\text { Pesquisa Bibliográfica de caráter } \\
\text { obrigatório. }\end{array}$ & $\begin{array}{l}\text { Sintomas de estresse pós- } \\
\text { traumático, sintomas } \\
\text { comórbidos como depressão } \\
\text { ansiedade, suicídio, abuso de } \\
\text { substâncias e distúrbios do } \\
\text { sono. }\end{array}$ \\
\hline
\end{tabular}

Fonte: As autoras (202I).

\section{ANÁLISE DE RESULTADOS}

Foi utilizada a análise descritiva para o processo de investigação dos dados obtidos, empregou-se o método de estatística descritiva que, segundo Reis e Reis (2002), tem como objetivo ordenar, sintetizar e detalhar os fatores relevantes de um conjunto de características analisadas.

Com base nos resultados encontrados, pode-se notar a prevalência de consequências psicológicas, como Transtorno de Estresse Pós-Traumático (TEPT), ansiedade, depressão, vergonha, medo, culpa, entre outros não menos relevantes.

O sofrimento psicológico que acomete mulheres vítimas de violência doméstica é uma das consequências que as impedem de viver saudavelmente, de 
maneira que a agressão pode resultar em um trauma, o qual afeta a mulher cognitiva e emocionalmente, gerando assim possíveis transtornos psicológicos (PEREIRA et al., 202I).

Dentre as consequências psicológicas está incluso o TEPT, F.43.10, que de acordo com o Manual Diagnóstico Estatístico DSM-V (2014), a angústia psicológica advinda de um episódio traumático ou de uma situação estressora é muito variável. Em algumas ocasiões, existe a possibilidade de os sintomas serem compreendidos em uma situação de ansiedade ou medo. O manual ainda pontua que o TEPT é muito mais comum e com maior duração em mulheres do que em homens, devido a uma probabilidade de essa população estar mais exposta a ambientes traumáticos, como abuso sexual e outros meios de violência. Além disso, a reincidência e a intensificação dos sintomas podem ocorrer devido as lembranças do trauma sofrido originalmente, das situações cotidianas estressantes ou de novos acontecimentos traumáticos. $O$ agravamento da saúde, das funções cognitivas, além do afastamento social, em relação as pessoas mais velhas, são meios que intensificam os sintomas de TEPT (DSM-V, 2014).

Amparadas com a Lei Maria da Penha e a Lei no 14.188 , que tipifica a violência psicológica, de acordo com Pereira et.al (2021), as mulheres no Brasil ainda são vítimas de seus companheiros que são oriundos de uma cultura machista, cuja sociedade colabora com o silêncio e a opressão que muitas ainda sofrem. Denúncias de assédio, violência física e psicológica são colocadas em dúvida julgando as mulheres como culpadas.

Uma forma de prevenção é conscientizar o maior número de mulheres através da divulgação de estudos com esse tema. Possibilitar discussões, reflexões e encorajamento para denúncias contra os agressores, a fim de minimizar o medo, a vergonha, a culpa e outros traumas acima mencionados.

Além disso, para reduzir a reincidência da violência e consequentemente dos traumas encontrados nos resultados, não cabe apenas focar no público que sofre essa agressão, mas também naquele que a provoca. Dessa forma, Prates (2013) pontua que a temática a respeito de criar lugares de reflexão para homens provocadores de violência tornou-se mais discutida e aceita. A autora ainda afirma que ao focar apenas no público feminino trabalharia somente com um dos componentes 
envolvidos no contexto de violência. No entanto, ao submeter os homens a um determinado meio de intervenção, possibilitaria reduzir a reincidência da violência em suas relações atuais e futuras.

\section{CONSIDERAÇÕES FINAIS}

O presente estudo buscou discorrer sobre a violência doméstica sofrida por mulheres e as consequências psicológicas pelas quais elas passam, com o intuito de ampliar o campo de pesquisa sobre um tema de tamanha relevância e infelizmente ainda atual, a partir de uma revisão bibliográfica.

Para compreender a temática estudada foi necessário levantar dados brasileiros sobre a incidência de violência doméstica e consequências psicológicas na população feminina, além de apontar e descrever os tipos dessa violência.

A pesquisa possibilitou concluir que existe uma grande quantidade de artigos com este tema, mas pouquíssimos com o mesmo foco, pois muitos estão direcionados a violência contra idosos, crianças, adolescentes, entre outros. Encontrou-se consequências severas de ordem psicológica que atingem as mulheres vítimas de violência doméstica, como TEPT, ansiedade, medo, isolamento social, angústia, vergonha, culpa, pânico, depressão, entre outros, não menos importantes.

Está nítido que há mudanças acontecendo nesse contexto, mas devido ao caráter da violência doméstica e aos preconceitos associados a ela, ainda há dificuldades a serem vencidas pela própria mulher que a sofre, como compreender que está sendo vítima desse processo cruel, o que torna um impeditivo para essa mulher buscar socorro.

A violência doméstica, que hoje é uma questão de saúde pública, a qual provoca grandes malefícios a comunidade, requer soluções urgentes, pertinentes e eficazes. Aponta-se a necessidade de mais estudos com o mesmo foco abordado, para possibilitar uma conscientização mais ampla da sociedade a respeito da gravidade dessa violência.

\section{REFERÊNCIAS}

AGÊNCIA PATRÍCIA GALVÃO. "Mas ele nunca me bateu": a importância prática da criação do crime de violência psicológica, por Beatriz Accioly Lins. São Paulo: Instituto Patrícia Galvão, 2021. Disponível em: 
<https://agenciapatriciagalvao.org.br/destaques/mas-ele-nunca-me-bateu-aimportancia-pratica-da-criacao-do-crime-de-violencia-psicologica-por-beatrizaccioly-lins/?print=pdf $>$. Acesso em: I4 ago. 202I.

ALVES, B. M.; PITANGUY, J. O que é Feminismo. São Paulo: Brasiliense, ı98ı.

ALVES, B. M.; PITANGUY, J. O que é feminismo. 8. Ed. São Paulo: Brasiliense, I991.

ASSMANN, S. J. Declaração dos Direitos da Mulher e da Cidadã. Revista Internacional Interdisciplinar Interthesis. Florianópolis, v.4, n.I, p. 2, 2007. Disponível em: <https://periodicos.ufsc.br/index.php/interthesis/article/viewFile/9II/Io852〉. Acesso em: 19 mar. 2021.

BATISTA, R. L.; BOTTINI, L. M. O Trabalho da Mulher Durante a Revolução Industrial Inglesa (1780 a 1850). Programa de Desenvolvimento Educacional da Secretaria de Estado da Educação. Paraná, v. I, p. 4-13, 2013. Disponível em: 〈http://www.diaadiaeducacao.pr.gov.br/portals/cadernospde/pdebusca/producoes_ pde/2013/2013_fafipa_hist_artigo_lucia_mamus_bottini.pdf $>$. Acesso em: I9 mar. 202I.

BANDEIRA, R. CNJ divulga dados do Judiciário sobre violência contra a mulher. Agência CNJ de Notícias, Brasília, 25 out. 2017. Disponível em: <http://www.cnj.jus.br/noticias/cnj/85640-cnj-publica-dados-sobre-violenciacontra-a-mulher-no-judiciario $\rangle$. Acesso em 28 abr. 2019.

BARBOSA, D. de O.; FONSECA, G. G. da. Violência doméstica e as consequências psicológicas sobre as vítimas. Revista Saúde e Educação, Coromandel, v. 4, n.I, p. I40-I73, jan./jun. 2019. Disponível em: 〈https://ojs.fccvirtual.com.br/index.php/REVISTA-SAUDE/article/ >. Acesso em: o8 mai. 2021.

BLAY, E. A. Violência contra a mulher e os regulamentos públicos. Estud. av. São Paulo, v. 17, n. 49, p. 87-98, dez. 2003. Disponível em 〈http://www.scielo.br/scielo.php?script=sci_arttext\&pid $=$ Soro30o6\&lng $=$ en $\& \mathrm{nrm}=$ is o>. Acesso em: 07 abr. 2019.

BRASIL. Lei n. II.340, de o6 de agosto de 2006. Dispõe sobre a criação dos Juizados de Violência Doméstica e Familiar contra a Mulher; altera o Código de Processo Penal, o Código Penal e a Lei de Execução Penal; e dá outras providências. Diário oficial da República Federativa do Brasil, Brasília, o6 ago. 2006. Disponível em: 〈http://www.planalto.gov.br/ccivil_03/_Ato2004-2006/2006/Lei/Lir340.htm>.

Acesso em: 07 abr. 2019.

BRASIL. Lei n. 13.104, de o9 de março de 2015. Altera o art. I2I do Decreto-Lei no 2.848, de 7 de dezembro de 1940 - Código Penal, para prever o feminicídio como circunstância qualificadora do crime de homicídio, e o art. Io da Lei no 8.072, de 25 de julho de 1990, para incluir o feminicídio no rol dos crimes hediondos. Diário oficial da República Federativa do Brasil, Brasília, o9 mar. 2015. Disponível em: 
〈http://www.planalto.gov.br/ccivil_03/_ato2015-2018/2015/lei/li3104.htm〉.

Acesso em: 28 abr. 2019.

BRASIL. Lei n. I4.I88, de 28 de julho de 202I. Diário oficial da República Federativa do Brasil, Brasília, 28 jul. 2021. Disponível em: 〈https://www.planalto.gov.br/ccivil_03/_Ato2019-2022/2021/Lei/Li4188.htm〉.

Acesso em: I4 ago. 2021.

BUENO, S.; BOHNENBERGER, M.; SOBRAL I. A violência contra meninas e mulheres no ano pandêmico. In: FÓRUM BRASILEIRO DE SEGURANÇA PÚBLICA - FBSP. Anuário brasileiro de segurança pública, São Paulo, 2021. Disponível em: <https://forumseguranca.org.br/wpcontent/uploads/202I/o7/anuario-202I-completo-v6-bx.pdf $\rangle$. Acesso em: 26 out. 202I.

BUONICORE, A. C. As mulheres e os direitos políticos no Brasil. In: NAZARIO, Diva Nolf. Voto feminino \& feminismo. São Paulo: Imprensa Oficial, 2009. Disponível

em:

〈http://www.nupemarx.ufpr.br/Trabalhos/Externos/BUONICORE_Augusto__As_mulheres_e_os_direitos_politicos_no_Brasil.pdf>. Acesso em: o8 mai. 202I.

CONSELHO FEDERAL DE PSICOLOGIA. Nota técnica de orientação profissional em casos de violência contra a mulher: casos para a quebra do sigilo profissional. [S.1.], 2016. Disponível em: 〈http://site.cfp.org.br/wpcontent/uploads/2016/II/Nota-tecnica-de-orientacao-profissional-para-casos-deviolencia-contra-a-mulher3.pdf $>$. Acesso em: o9 mai. 2019.

COUTO, M. T.; SCHRAIBER, L. B. Homens, saúde e violência: novas questões de gênero no campo da saúde coletiva. In: MINAYO, M. C. S.; COIMBRA JR, C. E. (Orgs.). Críticas e atuantes: Ciências Sociais e Humanas em Saúde na América Latina. (p. 687-706). Rio de Janeiro: Editora Fiocruz, 2005. Disponível em: $\langle$ https://static.scielo.org/scielobooks/w5p4j/pdf/minayo-9788575413920.pdf〉. Acesso em: o8 mai. 202I.

CREPSCHI, J. L. B. Significações psicológicas dadas a violência sexual por mulheres atendidas em ambulatório especializado universitário: um estudo clínico-qualitativo. I70 p. Tese (doutorado) - Universidade Estadual de Campinas, Faculdade de Ciências Médicas, Campinas, 2005. Disponível em: $\langle$ http://www.repositorio.unicamp.br/handle/REPOSIP/3II345>. Acesso em: 4 ago. 2018.

DEBERT, G. G.; GREGORI, M. F. Violência e gênero: novas propostas, velhos dilemas. Rev. bras. Ci. Soc., São Paulo, v. 23, n. 66, p. 165-185, Fev. 2008. Disponível em: $\langle$ http://www.scielo.br/scielosci_acdtrttext\&pid=Soro2-ooor \&lng=en\& $n r m=$ iso $>$. Acesso em: o8 mai. 202I.

FERNANDES, V. D. S.; ÁVILA, T. P de.; CUNHA, R. S. Violência psicológica contra a mulher: Comentários à Lei n. I4.188/2021. Disponível em: 〈https://meusitejuridico.editorajuspodivm.com.br/2021/o7/29/comentarios-lei-n882021/>. Acesso em: 28 ago. 2021. 
FÓRUM BRASILEIRO DE SEGURANÇA PÚBLICA. Anuário Brasileiro de Segurança Pública. Datafolha, ago. 2or6. Disponível em: <http://www.forumseguranca.org.br/storage/Io_anuario_site_18-II-2016retificado.pdf $>$. Acesso em: 28 abr. 2019.

GARCIA, C. C. Breve História do Feminismo. 3 ed. São Paulo, Claridade: 2015.

HAYECK, C. M. Refletindo sobre a violência. Revista Brasileira de História \& Ciências Sociais. São Leopoldo, v. I, n. I, p. or-o8, jan. - jun. 2009. Disponível em: 〈https://www.rbhcs.com/rbhcs/article/view/8/8〉. Acesso em: 31 mar. 2019.

INSTITUTO DE PESQUISA ECONÔMICA APLICADA. Atlas da Violência 202I. Brasília, 202I. Disponível em<https://www.ipea.gov.br/ aviolencompleto.pdf $>$. Acesso em: 19 set. 202I.

INSTITUTO DE PESQUISA ECONÔMICA APLICADA. Tolerância social da violência contra as mulheres. SIPS - Sistema de Indicadores de Percepção Social: São Paulo, 2014. Disponível em: <http://www.ipea.gov.br/portal/images/stories/PDFs/SIPS/I40327_sips_violencia_ mulheres.pdf $>$. Acesso em: 28 abr. 2019

KRUG, E. G. et al., (eds.) World report on violence and health. Geneva: World Health Organization, 2002. Disponível em: <https://www.opas.org.br/wpcontent/uploads/2015/o9/relatorio-mundial-violencia-saude.pdf $>$. Acesso em: 24 mar. 2019.

LAMBAZ, M. R. A violência contra a mulher no mundo contemporâneo: um estudo sobre a evolução das medidas protetivas no Brasil. Faculdades Integradas Rio Branco. Rio Branco, 2016. Disponível em: <http://conicsemesp.org.br/anais/files/2016/trabalho-I0000218ı6.pdf >. Acesso em: I9 mar. 2021.

MANUAL DIAGNÓSTICO E ESTATÍSTICO DE TRANSTORNOS MENTAIS: DSM-5 / [American Psychiatric Association; tradução: Maria Inês Corrêa Nascimento ... et al.]; revisão técnica: Aristides Volpato Cordioli...[et al.]. 5. ed. - Dados eletrônicos. - Porto Alegre: Artmed, 2014.

MARINELLI, B. Discriminação feminina no mercado de trabalho. Encontro De Iniciação Científica Do Centro Universitário Antônio Eufrásio De Toledo De Presidente Prudente. Presidente Prudente, v. I6, n. I6. p. I-II, 2020. Disponível em: 〈http://intertemas.toledoprudente.edu.br/index.php/ETIC/article/view/8705/6765 oIoo>. Acesso em: 19 mar. 2021.

MOURA, L. B. A. et al. Violência por parceiro íntimo contra mulheres em área urbana economicamente vulnerável, Centro-Oeste do Brasil. Rev. Saúde Pública, São Paulo, v. 43, n. 6, p. 944-953, dez. 2009. Disponível em: 〈http://www.scielo.br/scielo.php?script=sci_arttext\&pid=So03400oo5\&lng=en\&nrm =iso>. Acesso em: 07 abr. 2019. 
ORGANIZAÇÃO PAN-AMERICANA DA SAÚDE. Quase 60\% das mulheres em países das Américas sofrem violência por parte de seus parceiros. Banco de Notícias. Brasília, 29 nov. 2018. Disponível em: $\langle$ https://www.paho.org/bra/index.php?option=com_content $\&$ view $=$ article\&id=5812: quase-6o-das-mulheres-em-paises-das-americas-sofrem-violencia-por-parte-de-seusparceiros\&Itemid=820>. Acesso em: 04 mai. 2019.

OTTO, C. O feminismo no Brasil: suas múltiplas faces. Rev. Estud. Fem., Florianópolis, v. I2, n. 2, p. 238-24I, ago. 2004. Disponível em: 〈http://www.scielo.br/scielo.php?script=sci_arttext\&pid=So1040200015\&lng=en\&nr $\mathrm{m}=$ iso $>$. Acesso em: I8 mai. 2021.

PANEGHINI, L. R. Lutas feministas nos documentos do Conselho Federal de Serviço Social (CFESS): uma breve análise. Serv. Soc. Soc., São Paulo, n. 132, p. 252267, Ago. 2018

Disponível

em: $\langle$ http://www.scielo.br/scielo.php?script=sci_arttext\&pid=SoroI- =iso $>$. Acesso em: 28 abr. 2019.

PASINATO, W.; SANTOS, C. M. Mapeamento das Delegacias da Mulher no Brasil. Campinas: Pagu-Núcleo de Estudos de Gênero, Unicamp/Ceplaes/IDRC, 2008. Disponível em: 〈https://wwwi2.senado.leg.br/institucional/omv/entenda-aviolencia/pdfs/mapeamento-das-delegacias-da-mulher-no-brasil>. Acesso em: o8 mai. 202I.

PEREIRA, J. C. Consequências psicológicas da violência doméstica: uma revisão de literatura. Brazilian Journal of Health Review, Curitiba, v.4, n.4, p.I4736-I4752 jul. ago. 2021. Disponível em: $\langle$ https://www.brazilianjournals.com/index.php/BJHR/article/ /pdf〉. Acesso em: 28 ago. 2021.

PEREIRA, R. de C. B R. et al. O fenômeno da violência patrimonial contra a mulher: percepções das vítimas. Revista Brasileira de Economia Doméstica. Viçosa, v. 24, n.I, p.207-236, 2013. Disponível em: 〈https://www.locus.ufv.br/handle/123456789/13801〉. Acesso em: 28 mar. 202I.

PITTA, T. C.; OLIVEIRA, C. R. T. Violência psíquica contra a mulher: a necessária atuação estatal por meio de políticas públicas. Rev. Fac. Direito UFMG, Belo Horizonte, n. 6I, pp. I75 - 21I, jul. - dez. 2012. Disponível em: <https://www.direito.ufmg.br/revista/index.php/revista/article/view/P.03042340.2012v6ripi75/224>. Acesso em: o9 mai. 2019.

PRATES, P. L. A pena que vale a pena: alcances e limites de grupos reflexivos para homens autores de violência contra a mulher. São Paulo: tese defendida na Universidade de São Paulo Faculdade de Saúde Pública, 2013.

REIS, E. A.; REIS, I. A. Análise descritiva de dados. Relatório Técnico do Departamento de Estatística da UFMG, v. I, 2002. Disponível em: 〈http://www.est.ufmg.br/portal/arquivos/rts/rteo202.pdf〉. Acesso em: 07 set. 2021. 
SAFFIOTI, H. I. B. Contribuições feministas para o estudo da violência de gênero. Cad. Pagu, Campinas, n. I6, p. II5-136, 2001. Disponível em: 〈https://www.scielo.br/j/cpa/a/gMVfxYcbKMSHnHNLrqwYhkL/?lang=pt〉. Acesso em: 13 mar. 2021.

SANTOS, A. M. dos. A violência Contra a Mulher e os Diplomas Normativos que Tratam do Problema. 65 F. Monografia (Bacharelado em Direito) - Curso de Direito - Universidade Federal Fluminense: Instituto de Ciências da Sociedade, Macaé, 2018. Disponível

em: 〈https://app.uff.br/riuff/bitstream/I/8103/r/TCC\%2oFINAL\%2oPDF.pdf〉. Acesso em: 22 mar. 2021.

SANTOS, G. M. de C. A roupa, a moda e a mulher na Europa Ociental Medieval: reflexo da opressão sofrida pela mulher na Idade Média (século: XI-XV). 2006. I59 p. Dissertação (Mestrado em Artes) - Universidade de Brasilia, Brasília, 2006. Disponível em: 〈https://repositorio.unb.br/handle/I0482/6433〉. Acesso em: 22 mar. 2021.

SECRETARIA NACIONAL DE POLÍTICAS PARA AS MULHERES (SNPM). Enfrentando a violência doméstica e familiar contra a mulher. Ministério da Mulher, da Família e dos Direitos Humanos. República Federativa do Brasil: Brasília, 2020. Disponível em: <https://www.gov.br/ebserh/pt-br/comunicacao/noticias/ebserhapoia-acao-do-mfdh-que-visa-combater-violencia-contra-a-mulher/enfrentando-aviolencia-domestica-e-familiar-contra-a-mulher.pdf >. Acesso em: 26 out. 2021.

SCHRAIBER, L. B. et al. Violência dói e não é direito. São Paulo: Editora UNESP, 2005 .

SLEGH, H. Impacto psicológico da violência contra as mulheres. Outras Vozes, n. I5, mai. 2006. Disponível em: 〈http://www.wlsa.org.mz/artigo/impacto-psicologicoda-violencia-contra-as-mulheres/\#Nota . Acesso em: o9 mai. 2019.

SOUZA, C. L. et al. Violência moral contra a mulher no âmbito doméstico. Brazilian Journal of Development, Curitiba, v.7, n.9, p.89390-89402, set. 202I. Disponível em: $\langle$ https://www.brazilianjournals.com/index.php/BRJD/article/view/35907/pdf $\rangle$. Acesso em: 21 set. 2021.

TELES, M. A. de A. Breve história do Feminismo no Brasil e outros ensaios. São Paulo: Editora Alameda, 2017. Disponível em: <https://books.google.com.br/books?hl=pt-

$\mathrm{BR} \& 1 \mathrm{r}=\& \mathrm{id}=\mathrm{Ez}$ OD $\mathrm{OwAAQBAJ} \& o \mathrm{i}=\mathrm{fnd} \& \mathrm{pg}=\mathrm{PT} 3 \& \mathrm{dq}=$ feminismo + no + brasil\&ots $=z$ $\mathrm{n}_{3} \mathrm{EaBJizC} \& \operatorname{sig}=\mathrm{chFN}_{5} \mathrm{EpDw}_{\mathrm{w}} \mathrm{mIU}_{9}$ YOIDewywvaNl8\#v=onepage\&q\&f=true $>$.

Acesso em: 20 mar. 2021.

TOZONI-REIS, M. F. de C. Metodologia da Pesquisa. 2 ed. 2009. Disponível em: $<$ https://biblioteca.isced.ac.mz/bitstream/r23456789/785/I/METODOLOGIA\%2oD A\%2oPESQUISA.pdf $>$. Acesso em: 23 mai. 2021. 
WAISELFISZ, J. J. Mapa da Violência 20r5: Homicídio de mulheres no Brasil. I ed. Brasília: Faculdade Latino-Americana de Ciências Sociais, 2015. Disponível em: $\langle$ https://www.mapadaviolencia.org.br/pdf2015/MapaViolencia_2015_mulheres.pdf $\rangle$. Acesso em: 28 abr. 2019.

ZALESKI, M. et al. Violência entre parceiros íntimos e consumo de álcool. Rev. Saúde Pública, São Paulo, v. 44, n. I, p. 53-59, fev. 2010. Disponível em: $<$ http://www.scielo.br/scielo.php?script=sci_arttext\&pid=Soo3489102010000100oo6\&lng=en\& $\mathrm{nrm}=$ iso $>$. Acesso em: 30 mai. 2019. 